\title{
Pregnancy with extrahepatic portal venous hypertension
}

\author{
Shilpa Nabapure, Sapna I. S., Balumuri Pooja Sai*
}

Department of Obstetrics and Gynecology, SSIMS and RC, Davangere, Karnataka, India

Received: 22 February 2021

Revised: 16 April 2021

Accepted: 17 April 2021

\section{*Correspondence:}

Dr. Balumuri Pooja Sai,

E-mail: poojabalumuri11@gmail.com

Copyright: (C) the author(s), publisher and licensee Medip Academy. This is an open-access article distributed under the terms of the Creative Commons Attribution Non-Commercial License, which permits unrestricted non-commercial use, distribution, and reproduction in any medium, provided the original work is properly cited.

\begin{abstract}
We are reporting a case of pregnancy with extrahepatic portal venous hypertension. Portal hypertension in pregnancy is an uncommon event. It presents a challenge to the obstetrician in management as physiological hemodynamic changes associated with pregnancy worsen with portal hypertension. Thus, increasing risk of life threatening complications like variceal haemorrhage and hepatic decompensation to many folds during pregnancy. Management requires knowledge of effects of portal hypertension on maternal and fetal outcome and vice-versa.
\end{abstract}

Keywords: EHPVH, HPVG. Pregnancy

\section{INTRODUCTION}

Extrahepatic portal hypertension in absence of liver cirrhosis and especially in pregnancy is rare. ${ }^{1}$ It can occur in about $15 \%$ of patients with idiopathic non cirrhotic portal hypertension in women of childbearing age group. ${ }^{2}$

The hepatic venous pressure gradient is the gold standard to measure the portal pressure to guide the management and prognosis of patients. ${ }^{4}$ HVPG $>10 \mathrm{mmhg}$ for esophageal varices to appear, HVPG >12 mmhg for varices to bleed.

There is $45 \%$ increase in plasma volume during pregnancy leading to increased portal pressure and increasing the overall risk of variceal bleeding. About 30$50 \%$ of patients suffer from portal hypertension related complications, mainly variceal bleed and hepatic failure. ${ }^{5}$ The other complications that can occur include upper GI bleed, ascites, splenomegaly, thrombocytopenia secondary to splenomegaly, jaundice, hyperdynamic circulation, pulmonary complications, portosystemic encephalopathy secondary to increase portosystemic collateral circulation and mild preeclampsia, preterm labour and anaemia.

\section{CASE REPORT}

A 32 year old lady primigravida presented to SSIMS and $\mathrm{RC}$ with 5 months of amenorrhoea and is known case of extrahepatic portal venous hypertension. She had regular antenatal checkups, 1 st and 2nd trimester were uneventful. In 3rd trimester she was diagnosed as GDM and was started on medical nutrition therapy. She was diagnosed as extra hepatic portal venous hypertension (EHPVH) 2.5 years back incidentally on a USG scan which revealed chronic liver disease with mild splenomegaly. So was evaluated further with CECT abdomen and pelvis which revealed moderate splenomegaly with prominent splenic vein along with perisplenic gastro-esophageal collaterals with prominent portal vein and dorsal pancreatic agenesis. Her peripheral blood smear showed normocytic hypochromic anemia with pancytopenia and her bone marrow biopsy was normal. She was started on tablet propranolol $40 \mathrm{mg}$ for 
1 year following which she conceived spontaneously and presented to us at 5th month of ammenorhoea. Patient underwent upper GI endoscopy which revealed no esophageal varices. Her blood reports were normal except for persistent thrombocytopenia. Admission was advised at 35 weeks gestation; gastroenterologist opinion taken and opined that patient carries moderate risk of hepatic decompensation with MELD score 7. She was transfused 5 pints platelets in view of thrombocytopenia and she was taken up for emergency caesarean section in view of fetal distress. Intraoperatively straw yellow coloured amniotic fluid drained. Postoperatively syrup lactulose was put HS to avoid constipation. Her puerperal period was uneventful and she was discharged on day 7 after suture removal.

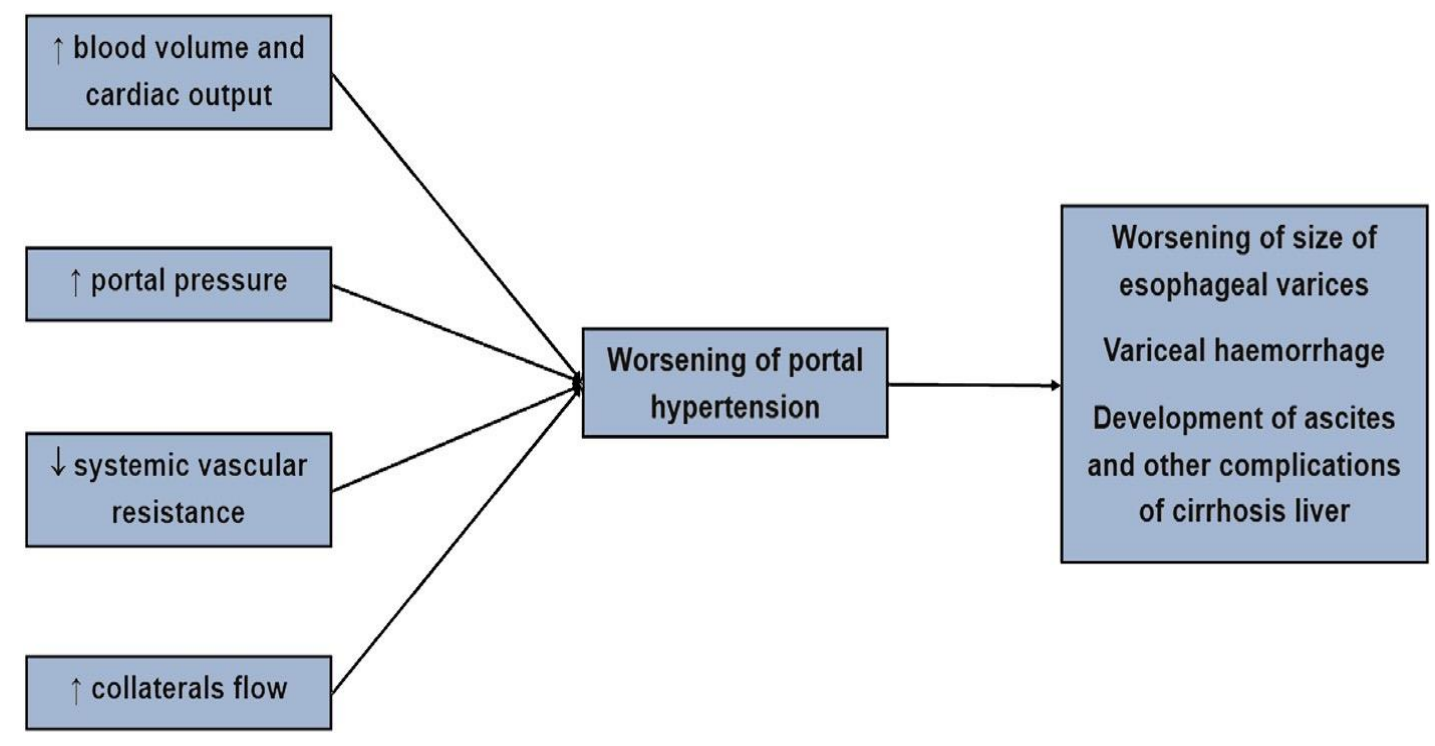

Figure 1: Effects of haematological changes in pregnancy on portal hypertension.

\section{DISCUSSION}

Prognosis depends upon the underlying cause and extent of derangement of liver function. Management of portal hypertension in pregnant women is similar to that in nonpregnant woman. $\beta$-blockers are given to reduce the portal venous pressure. Surgical management by banding, sclerotherapy and shunt surgery during 2 nd trimester can be done. There is danger of variceal rupture and hematemesis when patient strains during labor. ${ }^{6}$ But patient with extrahepatic portal venous hypertension with non-cirrhotic portal fibrosis generally tolerate labor and caesarean section is not mandatory. They can be given a trial of labor. They must not to allowed to bear down and second stage should be cut short. maternal mortality ranges from 2 to $18 \%$ (being more with cirrhosis) where the causes of death are generally hematemesis, hepatic coma or postpartum haemorrhage. Perinatal mortality ranges between $11 \%$ to $18 \%$ due to preterm delivery and IUGR. $^{7}$ Prenatal obliteration of varices either by endoscopic variceal ligation (EVL) or endoscopic sclerotherapy reduces the risk of complications and certainly improves the perinatal outcome. ${ }^{8}$

\section{Preconceptional counselling}

Extensive and detailed preconceptional counselling especially in presence of poor predictors like history of variceal bleed, large varices, presence of comorbidities like jaundice, thrombocytopenia, ascites, hypersplenism should be done. Surveillance endoscopy should be done in preconceptional period. ${ }^{9}$

\section{Antenatal management}

The goals of management of patients with portal hypertension include early diagnosis and management of complications. Pregnancy is not a contraindication if the disease is well compensated. Liver function tests and haematological assessment should be done 4 weekly. Anaemia should be prevented and treated. American association for study of liver disease (AASLD) recommends screening endoscopy in the second trimester as that is the time for maximum increase in portal pressure. ${ }^{10}$ But risk of fetal hypoxia during sedation and positioning should be kept in mind. Prophylaxis of nonselective $\beta$-blockers are given to reduce portal pressure but side effects include fetal growth restriction, fetal bradycardia, neonatal hypoglycaemia.

\section{Peripartum management}

Adequate amount of blood and blood products should be arranged. Platelet transfusion may be needed in cases of hypersplenism. Epidural analgesia is preferred. Second stage of labor may be shortened prophylactically to avoid over straining by the mother. Active management of $3 \mathrm{rd}$ 
stage of labor should be done. Among the oxytocics, methergin should be avoided.

\section{Postpartum management}

The postpartum management includes strict vigilance for postpartum hemorrhage. Antibiotics should be given in the postpartum period. Reliable contraception must be advised in the form of barrier methods, intrauterine devices or permanent sterilization. However, permanent sterilization may not be feasible in the presence of coagulopathy. Hormonal contraception is usually avoided as they can cause cholestasis. ${ }^{11}$

\section{CONCLUSION}

The risk of variceal bleeding may be increased in pregnancy in patients with non-cirrhotic portal hypertension but pregnancy can still be allowed and managed successfully under supervision. It is a multidisciplinary approach including expert obstetrician, hepatologist, neonatologist and anesthesiologist in a teritiary care centre with facilities and expertise for gastrointestinal endoscopy, portal vascular surgery, high risk pregnancy unit, perinatal and adult intensive care unit.

\section{Funding: No funding sources}

Conflict of interest: None declared

Ethical approval: Not required

\section{REFERENCES}

1. Peitsidou A, Peitsidis P, Michopoulos S, Matsouka C, Kioses E. Exacerbation of liver cirrhosis in pregnancy: a complex emerging clinical situation. Arch Gynecol Obstet. 2009;279(6):911-3.

2. Sarin SK, Sollano JD, Chawla YK, Deepak Amarapurkar, Saeed Hamid, Hashizume M, et al.
Consensus on extra-hepatic portal vein obstruction. Liver Int. 2006;26(5):512-9.

3. Van Dyke RW. The liver in pregnancy. In: Zakin D, Boyer TD, eds. Hepatology: a text book of liver disease. 3rd ed. Philadelphia: WB Sauders; 1996: 1734-59.

4. Cheng YS. Pregnancy in liver cirrhosis and/or portal hypertension. Ame J Obstetr Gynecol. 1977;128(7): 812-22.

5. Üstüner I, Akdoğan RA, Güven ESG, Sahin FK, Sentürk S, Adogan E, et al. Pregnancy in the setting of asymptomatic non-cirrhotic chronic portal vein thrombosis complicated by pre-eclampsia. Case Rep Obstet Gynecol. 2013;2013:984271.

6. Misra S, Sanyal AJ. Pregnancy in a patient with portal hypertension. Clin Liver Dis. 1999;3:147-62.

7. Hoekstra J, Seijo S, Rautou PE, G Ducarme, Boudaoud L, Luton D, et al. Pregnancy in women with portal vein thrombosis: results of a multicentric European study on maternal and fetal management and outcome. J Hepatol. 2012;57(6):1214-9.

8. Rajekar H, Vasishta RK, Chawla YK, Dhiman RK. Non-cirrhotic portal fibrosis: current concepts and management. J Gastroenterol Hepatol. 2002;17(5):526-34.

9. Varma RR, Bokowf HI, Lewis JD. Pregnancy in cirrhotic and non-cirrhotic portal hypertension. Obstetr Gynaecol. 1977;50(2):217-22.

10. Mahadevan U, Kane S. American gastroenterological association institute technical review on the use of gastrointestinal medications in pregnancy. Gastroenterology. 2006;131(1):283-311.

11. Varma RR, Michelson NH, Borkowf HI, Lewis JD. Pregnancy in cirrhotic and non-cirrhotic portal hypertension. Obstetr Gynecol. 1977;50(2):217-22.

Cite this article as: Nabapure S, Sapna IS, Sai BP. Pregnancy with extrahepatic portal venous hypertension. Int J Reprod Contracept Obstet Gynecol 2021;10:2085-7. 